Bojana Budimir

Universiteit van Belgrado

https://doi.org/10.18485/bgd_nlistiek_30.2018.ch9

\title{
VAN LIBERAAL NAAR GIERIG: BEELDVORMING BIJ STUDENTEN NEERLANDISTIEK IN BELGRADO, SERVIË
}

\begin{abstract}
Until not so long ago it was assumed that learning languages is by far the most effective way to overcome stereotypes. However, recent studies make it clear that it takes a lot more than the pure exposure to the target language and its culture to fight these unfortunate preconceived notions. Language students not only enter the classroom with stereotypical images about the target culture, they also come across a great amount of stereotypical representations and overgeneralizations in the school materials during their learning process. The aim of the present case study is to examine the stereotypical images of Dutch language students in Serbia before and after their study period in order to establish the influence of direct exposure to the language and the culture on the formation of stereotypes about the Dutch and the Flemish.
\end{abstract}

Keywords: stereotypes, representation, generalization, second language acquisition, intercultural communication, Dutch studies

\section{Inleiding}

Hoewel het onderzoek naar het fenomeen van stereotypen reeds een lange traditie kent, blijft het nog steeds een moeilijk te definiëren term. Wel is men het er over eens dat het gaat om vooringenomen ideeën betreffende individuen, groepen of gebruiken. Zijn stereotypen per definitie slecht en negatief, foutief en vast, moeten ze beschouwd worden als een groepsfenomeen of een fenomeen op het niveau van het individu, dat zijn maar enkele vragen die onderzoekers uit verschillende invalshoeken (o.a. sociaalcultureel, psychodynamisch en cognitief) proberen te belichten.

Volgens vele auteurs werd de term stereotype in de sociale wetenschappen voor het eerst geïntroduceerd door Walter Lippman in zijn publicatie Public Opinion uit 1922. Hoewel Lippman zelf geen expliciete definitie van de term gaf, wordt er in de literatuur vaak verwezen naar de zin uit het eerste hoofdstuk van zijn boek, met name naar de frase 'pictures in our heads', om dit verschijnsel te verklaren (Ashmore \& Del Boca, 1981). Volgens Lippman zijn stereotypen slechts een middel om de perceptie en cognitie van een realiteit die te complex is om in haar geheel waargenomen te worden, te vereenvoudigen. Deze opvatting sluit eigenlijk aan bij de verklaringen van stereotypen binnen de cogintieve benadering. In deze benadering worden stereotypen 
verklaard als een middel om complexe informatie uit onze omgeving efficiënt te verwerken en dat door middel van categorisering. Veel onderzoek in het kader van de cognitieve benadering suggereert dat '[...], stereotypes is a characteristic of us all' (Hinton 2000: 131). Als dusdanig zijn ze eigenlijk onvermijdelijk.

Lang werd er gedacht dat stereotypen juist door het leren van nieuwe talen ontkracht kunnen worden. Volgens Byram en Morgan (1994) bracht onderzoek naar deze problematiek aan het licht dat enkel de blootstelling aan een nieuwe taal en het leren over nieuwe culturen niet noodzakelijk tot een positieve houding tegenover de doelcultuur leiden.

Attitude formation and attitude change are complex processes and mere exposure to language learning and information about other cultures will not necessarily lead to the desired results. There are complex relationships between cognitive and affective components of attitudes towards other peoples, between information and the ways in which it is presented, between general psychological development and specific development of perceptions of foreign and native cultures and countries (Byram \& Morgan 1994: 40).

Allport (1954) merkte al op dat een betere kennismaking met een bepaalde cultuur, hoewel één van de voorwaarden om stereotiepe voorstellingen en vooroordelen te doorbreken, niet altijd een positieve houding tegenover de cultuur in kwestie met zich meebrengt.

Those who know the most about other races and peoples tend to have favorable attitudes about them. However, while we tend to feel friendly to those nations about which we have most knowledge, we likewise have considerable knowledge about those nations we hate. In other words, the law of the inverse relations between knowledge and hostility fails to hold at the extreme degree of hostility (Allport, zoals geciteerd in Matusitz, 2001: 93).

Aangezien taal en cultuur niet te onderscheiden zijn, leren studenten samen met de taal onvermijdelijk ook de doelcultuur kennen. Leermethodes- en materialen, boeken (zowel fictie als non-fictie) en andere teksten waarmee studenten tijdens hun studie in contact komen door extracurriculaire activiteiten, zitten vol representaties van de doelcultuur die vaak stereotiep van aard zijn en die tot generalisaties kunnen leiden. Om die reden is er in het kader van interculturele communicatie aandacht besteed aan de manier waarop cultuur effectief geïntegreerd kan worden in het vreemde talenonderwijs om stereotypering te voorkomen. Byram, Gribkova \& Starkey (2002: 9) leggen de nadruk op het ontwikkelen van kritisch denken en '[...], perceiving the interlocutor as an individual whose qualities are to be discovered, rather than as a representative of an externally ascribed identity'. De auteurs stellen dat de kennis (savoirs) over andere culturen slechts een onderdeel van dit proces vormt naast vaardigheden (interpretatievermogen of savoir comprendre en lerend vermogen ofwel 
savoir apprendre/faire), houdingen (openheid en nieuwsgierigheid of savoir être) en besef van verschillende waarden (savoir séngager). Bij het behandelen van stereotypen is laatstgenoemde van het grootste belang.

The concept of savoir sengager suggests that teachers should first challenge learners to make explicit the basis on which they make judgements about others, and to encourage them to be aware of the culturally-determined nature of their basis for making judgements. This $[s i c]$ not the same as challenging and criticizing learners' beliefs and basis for judgement about other cultures. It is simply an encouragement to them to see how others might consider their position, whether it is religious, secular, ethical, philosophical or pragmatic (Byram, Gribkova \& Starkey 2002: 36).

Het doel van hierna gepresenteerde kleinschalige studie is inzicht te krijgen in de stereotiepe voorstellingen van Servische studenten voor en na hun studie Neerlandistiek. De term stereotype wordt hier gebruikt in de ruimste zin. Daaronder wordt verstaan :a set of beliefs about the personal attributes of a group of people' (Ashmore \& Del Boca, 1981). Daarbij zal de aandacht vooral gaan naar de volgende vragen: Welke stereotypen hebben eerstejaarsstudenten over Nederlanders en Vlamingen en welke vierdejaarsstudenten en afgestudeerden? Zijn die positief of negatief? Wat voor kennis hebben ze tijdens hun studie opgedaan? Waar hebben ze de meeste kennis vandaan gehaald? En in welke verhouding staat de verworven kennis tot hun voorstellingen over de doelculturen?.

\section{De context van het onderzoek}

De Lage Landen en Servië liggen niet alleen geografisch maar ook cultureel en historisch gezien ver uit elkaar. Door de geschiedenis heen hadden ze nauwelijks met elkaar te maken en daardoor weten ze eigenlijk weinig van elkaar.

De Nederlandse taal, literatuur en cultuur worden sinds 1987 onderwezen aan de Filologische Faculteit te Belgrado, aanvankelijk als bijvak en vanaf 2002 als hoofdvak. De bachelor neemt vier jaar in beslag en daarnaast wordt ook een éénjarig masterprogamma aangeboden. Tijdens hun studie krijgen de studenten vakken zoals taalverwerving, Nederlandse en Vlaamse literatuur, kunst- en cultuurgeschiedenis van Nederland en Vlaanderen, alsook vakken waarbij ze zich bezighouden met de verhoudingen tussen de Lage Landen en Servië. Ze krijgen lessen van zowel inheemse als buitenlandse (moedertaalsprekers) docenten, maar het moment waarop de participanten voor het eerst in contact komen met de buitenlandse lector(en) hangt af van de generatie waartoe ze behoorden. In totaal gaven er sinds 2002 acht buitenlandse lectoren les aan het departement Neerlandistiek, waarvan vier Vlaamse en vier Nederlandse die tussen zes maanden tot vijf jaar werkzaam waren aan de vakgroep. De meeste participanten in de enquêtes hadden ook de mogelijkheid om één van de zomercursussen in Nederland (Zeist) of Vlaanderen (Leuven, Gent, Hasselt) bij te wonen. 


\section{Methode}

Om inzicht te krijgen in de stereotiepe voorstellingen over Nederlanders en Vlamingen van de studenten Neerlandistiek te Belgrado, zowel voor als na hun studie, heb ik de resultaten van de enquêtes die elk jaar afgenomen worden onder de nieuw ingeschreven studenten vergeleken met de restultaten van de ênquete onder de vierdejaarsstudenten en afgestudeerden.

\section{Dataverzameling}

Elk jaar, bij de officiële ontvangst aan het begin van het academiejaar, krijgen de nieuw ingeschreven studenten een formulier met vragen over hun ervaringen met Nederland en Vlaanderen, hun voorkennis over de genoemde culturen, evenals hun motivatie en verwachtingen van de studie. Voor dit onderzoek heb ik de enquêtes van de studenten die ingeschreven zijn tussen 2009 tot en met 2012 geanalyseerd, waarbij ik mijn aandacht op de volgende vragen heb gericht: Ben je ooit in Nederland en/of Vlaanderen geweest? Welke eigenschappen associeer je met Nederlanders en welke met Vlamingen? Waarom heb je voor de studie Nederlands gekozen? Er werden antwoorden van in totaal zesenzeventig participanten onder de loep genomen.

Om inzicht te krijgen in de stereotiepe voorstellingen van studenten na hun studie heb ik in 2015 een vragenlijst opgesteld met Google Forms, om deze vervolgens te e-mailen richting studenten Neerlandistiek die ingeschreven waren in de periode tussen 2009 en 2012 en die toen in het vierde jaar zaten of afgestudeerd waren. 31 respondenten hebben de moeite genomen om de vragenlijst te beantwoorden. De vragenlijst bevatte de volgende vragen: Ben je ooit in Nederland en/of Vlaanderen geweest? Welke eigenschappen associeer je met Nederlanders en welke met Vlamingen? Daarnaast werden de respondenten gevraagd om op een Likertschaal (1 helemaal oneens, 5 helemaal eens) aan te duiden in welke mate de informatie over de culturele referenties die ze tijdens hun studie verkregen hebben betrekking hebben op de zichtbare, halfzichtbare of onzichtbare cultuur. Er werd ook gevraagd naar hun ervaring met stereotypen tijdens de studie.

\section{Resultaten}

Welke voorstellingen over Nederlanders en Vlamingen hebben de nieuw ingeschreven studenten?

Zoals Dlaska (2000: 260) opmerkte, zijn al bij de beginnende studenten stereotypen aanwezig. Ze betreden het klaslokaal met bepaalde voorstellingen over de doelcultuur (en de leden daarvan) hoewel ze in de meeste gevallen nog geen direct contact met de doelcultuur hadden. Het was derhalve interessant te zien of dat ook voor de Servische studenten Neerlandistiek gold.

Uit de resultaten bleek dat maar zes van de zesenzeventig eerstejaarsrespondenten (8\%) in Nederland zijn geweest, terwijl slechts twee studenten (3\%) ooit Vlaanderen hebben 
bezocht. Daaruit valt te concluderen dat onze studenten bijna geen direct contact met de Nederlandse en Vlaamse cultuur hebben voordat ze aan hun opleiding beginnen.

$96 \%$ van de studenten heeft zelfs geen enkele associatie m.b.t. Vlamingen, terwijl $61 \%$ van de respondenten geen enkel kenmerk aan de Nederlanders heeft toegeschreven. Wat de kenmerken betreft die de overige studenten ( 29 in totaal) m.b.t. Nederlanders wel hebben genoemd, blijkt dat ze over het algemeen een zeer positief beeld van Nederlanders hebben. Er zijn in totaal vijfentwintig attributen genoemd. De meeste kenmerken die door studenten aangegeven zijn, zijn positief: ze beschouwen Nederlanders voornamelijk als vriendelijk en liberaal, maar er werden ook eigenschappen zoals zorgeloos, ontspannen en communicatief aangeduid. Er verschenen maar twee negatieve kenmerken, met name dat ze koel en gereserveerd zijn.

Uit de motivatie en verwachtingen van onze studenten is ook een positief beeld ten opzichte van Nederland af te lezen. De meeste studenten hebben voor de studie Nederlands gekozen, omdat ze de taal leuk, interessant en bijzonder vinden (42\%) maar ook omdat ze interesse hebben voor de Nederlandse cultuur en maatschappij (17\%), die volgens de studenten indrukwekkend en fascinerend zijn. Het is daarnaast ook relevant dat enkele studenten $(12 \%)$ voor het Nederlands gekozen hebben omdat het op het Duits lijkt.

Welke voorstellingen over Nederlanders en Vlamingen hebben de vierdejaarsstudenten en afgestudeerden?

Terwijl de overgrote meerderheid van de nieuw ingeschreven studenten nooit voor hun studie Nederland of Vlaanderen bezocht hebben, is dit na hun studie helemaal veranderd. Slechts vier van de éénendertig respondenten zijn nooit in Nederland of Vlaanderen geweest. De rest heeft tenminste één keer tijdens hun studie één van die twee landen bezocht. $74 \%$ van de studenten heeft wel eens Nederland bezocht, terwijl $55 \%$ ooit in Vlaanderen was geweest.

Wat voor impact heeft dit directe contact met de doelcultuur dus gehad op hun voorstellingen van Nederlanders en respectievelijk Vlamingen? Hadden de studenten voor hun studie bijna geen voorstellingen over Vlamingen en kon minder dan de helft een kenmerk aan Nederlanders toeschrijven, dan heeft nu $97 \%$ van de studenten een 'beeld' van Nederlanders en 69\% van Vlamingen. Er zijn zelfs tweeëndertig kenmerken aan de Nederlanders toegeschreven en vierentwintig aan de Vlamingen. Hoewel hun beeld van Nederlanders in het algemeen positief is gebleven, is uit de resultaten gebleken dat onze studenten zich intussen ook negatieve voorstellingen over Nederlanders hebben gemaakt. Volgens de meeste studenten (54\%) zijn Nederlanders spaarzaam, maar $32 \%$ van de studenten noemt een woord met een negatieve connotatie, met name dat ze gierig zijn. In het algemeen vindt $87 \%$ dat Nederlanders niet zo graag geld uitgeven. Als we dit in een bredere context plaatsen, is het stereotiepe beeld over gierige Nederlanders geen nieuwtje. Deze eigenschap werd al in de zeventiende eeuw aan de Nederlanders toegeschreven (Van Ginkel, 1996) en het heeft zelfs zijn weg gevonden naar het Engels, één van de meest gesproken talen, en dit in de frase 'to go Dutch'. 
Daartegenover hebben de respondenten een veel positiever beeld van Vlamingen dan van Nederlanders. Vlamingen zijn - aldus de respondenten - sociaal, aardig en open (zie Tabel 1). Er kwamen ook vergelijkingen voor in de antwoorden van de studenten, zoals bv. Vlamingen zijn meer ontspannen en meer open dan Nederlanders. Het is ook interessant dat één van de studenten een stereotiep beeld van Nederlanders over Vlamingen overneemt en aangeeft dat 'de Nederlanders Vlamingen stom vinden'.

\begin{tabular}{l|l|l|l} 
Nederland & $\begin{array}{l}\text { aantal keer } \\
\text { genoemd }\end{array}$ & Vlaanderen & $\begin{array}{l}\text { aantal keer } \\
\text { genoemd }\end{array}$ \\
\hline spaarzaam & 17 & sociaal & 5 \\
\hline gierig & 10 & aardig & 5 \\
\hline stipt & 8 & open & 5 \\
\hline tolerant & 4 & ontspannen & 3 \\
\hline gereserveerd & 3 & vrolijk & 2 \\
\hline goed georganiseerd & 2 & hedonistisch & 2 \\
\hline & & ijverig & 2 \\
\hline & & spaarzaam & 2 \\
\hline & & patriottistisch & 2 \\
\hline
\end{tabular}

Tabel 1

Deze resultaten zijn vooral interessant als we naar hun antwoorden kijken op de vraag of hun stereotiepe voorstellingen tijdens hun studie ontkracht zijn. Dertig studenten hebben met 'ja' geantwoord en slechts één student geeft aan dat hij zijn vooroordelen bevestigd heeft gezien, alsook dat hij nieuwe stereotiepe beelden van Vlamingen heeft geconstrueerd. Daaruit valt te concluderen dat onze studenten toch niet beseffen dat ze nog steeds stereotiepe voorstellingen over Nederlanders en Vlamingen koesteren, zoals we aan de hand van de bovengenoemde stereotypen kunnen zien.

\section{Discussie}

Waar kan dit dan aan liggen? Eén van de redenen kan de aard van de informatie zijn die ze over de broncultuur tijdens hun studie hebben verkregen hebben. Op de vraag of ze hun kennis van de Nederlandse en Vlaamse cultuur verdiept hebben tijdens hun studie, geven de respondenten een heel hoog cijfer, nl. 4,48/5 en 4,35/5 als het om de Nederlandse en resp. Vlaamse cultuur gaat. De respondenten werdook gevraagd om op een vijfpuntenschaal ( 1 helemaal oneens, 5 helemaal eens) aan te duiden in welke mate de informatie over de culturele referenties, die ze tijdens hun studie verkregen, betrekking hebben op de zichtbare, halfzichtbare of onzichtbare cultuur. ${ }^{1}$

1 Volgens het model van Hall (1990) wordt er onder zichtbare cultuur o.a. muziek, kunst, eten en drinken, kleding, architectuur, aardrijkskunde e.d. verstaan. Halfzichtbare cultuur bevat normen en regels waardoor zowel schriftelijke als mondelinge communicatie geregeld wordt. Het laatste niveau is de zogenaamde onzichtbare cultuur, dwz. het cognitieve systeem en de waarden van een maatschappij. 
Uit de resultaten valt te concluderen dat de studenten wat meer informatie over normen, regels, gewoontes en gedragsmodellen voorgeschoteld hebben gekregen en wat minder kennis gemaakt hebben met de waarden en ideeën die erachter schuilen (zie Tabel 2). Deze resultaten komen overeen met een eerder verricht onderzoek naar de praktijken van de docenten Nederlands in de regio van Centraal- en Oost Europa, waaruit bleek dat ze de meeste aandacht aan de halfzichtbare, ofwel formele cultuur besteden (Budimir, 2015). Voor een goed begrip van de cultuur is het belangrijk dat we de principes kennen en begrijpen die ten grondslag liggen aan zowel de zichtbare als onzichtbare cultuur.

\begin{tabular}{l|l|l} 
& $\begin{array}{l}\text { Nederlandse } \\
\text { cultuur (gem.) }\end{array}$ & $\begin{array}{l}\text { Vlaamse } \\
\text { cultuur (gem.) }\end{array}$ \\
\hline $\begin{array}{l}\text { Technische cultuur } \\
\text { (zichtbare cultuur, eg. muziek, kunst, } \\
\text { architectuur, kleding) }\end{array}$ & 3,87 & 3,87 \\
\hline $\begin{array}{l}\text { Formele cultuur } \\
\text { (halfzichtbare cultuur, eg. normen, } \\
\text { regels, gewoontes, gedragsmodellen) }\end{array}$ & 4,29 & 4 \\
\hline $\begin{array}{l}\text { Informele cultuur } \\
\text { (onzichtbare cultuur, eg. waarden, } \\
\text { ideeën, geloof) }\end{array}$ & 3,87 & 3,58 \\
\hline
\end{tabular}

Tabel 2

Een ander belangrijk punt dat uit de resultaten kan worden afgeleid, is het belang dat aan het ontwikkelen van kritisch denken in het behandelen van stereotypen zou moeten worden gehecht, wat Byram, Gribkova \& Starkey (2002) savoir s'engager noemen. Het ontkrachten van stereotypen is een langdurig proces dat systematisch en geleidelijk opgebouwd zou moeten worden. Uit een onderzoek naar de praktijken van docenten taalverwerving in Centraal- en Oost Europa is gebleken dat de meeste docenten wel aandacht aan stereotypering tijdens hun lessen besteden en dat ze studenten stimuleren om er kritisch over na te denken door middel van discussie en opdrachten waarbij studenten bron- en doelcultuur naast elkaar leggen, maar het bleek dat het toch nog aan een systematische aanpak van dit fenomeen ontbreekt. (Budimir 2015: 10). Aangezien taalverwerving slechts een onderdeel van de opleiding vormt, zou er ook een onderzoek naar de praktijken van docenten verricht moeten worden die vakken zoals letterkunde en kunst- en cultuurgeschiedenis geven om het beeld van stereotypering in de cultuuraanpak helder te krijgen. 


\section{Conclusie}

Aangezien de contacten tussen de Lage Landen en Servië dun gezaaid en sporadisch zijn, is het ontbreken van voorstellingen over Nederlanders en Vlamingen niet te verwonderen. In het geval van Vlamingen en Vlaanderen is het vrij goed mogelijk dat de meeste studenten er nooit van gehoord hebben en bestaat er een grote kans dat de resultaten anders zouden zijn als er in de vragenlijst België en Belgen in plaats van resp. Vlaanderen en Vlamingen had gestaan. Individuen kunnen wel stereotiepe voorstellingen over bepaalde groepen hebben, hoewel ze nooit in contact zijn gekomen met de leden van die groep, maar om over culturele stereotypen (stereotypen die gedeeld zijn door een grote groep) te kunnen praten, moet er toch wat intensiever contact, direct of indirect (via media, literatuur, films, muziek, sport, enz.) bestaan. Anderzijds bevestigen de resultaten van de enquêtes onder de vierdejaarsstudenten de stelling van Byram en Morgan (1994) dat louter het leren van de taal en het kennis maken met de cultuur onvoldoende zijn om stereotypering in te dijken, te beperken of te voorkomen. Het feit dat de studenten voor hun studie bijna geen voorstellingen hebben, terwijl ze vier jaar later, na een kennismaking met de doelcultuur en deze op allerlei manieren te hebben bestudeerd, zich wel bepaalde stereotiepe voorstellingen hebben gemaakt, is zeker belangwekkend.

Ten slotte kunnen we concluderen dat er tijdens de studie zeker meer aandacht besteed moet worden aan de principes die aan de grondslag liggen aan literatuur, kunst, muziek, gedrag, gewoontes, enz. Daarbij dient echter niet alleen naar de andere cultuur gekeken te worden maar ook naar de eigen cultuur. Juist vanuit een contrastieve benadering krijgt men een groter en beter begrip van zichzelf, maar ook van de ander. Daarnaast wil ik ook het belang van direct en regelmatig contact met de broncultuur onder de aandacht brengen. Volgens de contacthypothese (Allport, 1954) zijn er twee belangrijke voorwaarden waaraan voldaan moet worden voor het ontkrachten van stereotypen en vooroordelen: met name regelmatig contact en persoonlijke relaties met de leden van andere groepen. In de concrete situatie in Servië spelen daarbij vooral de moedertaalsprekers een belangrijke rol, aangezien zij de enige vertegenwoordigers van de broncultuur zijn met wie studenten dagelijks contact kunnen hebben, alsook de zomercursussen waar ze niet alleen met de brontaalcultuur in contact komen maar eveneens met andere culturen. Toch moet dit allemaal gekoppeld worden aan het ontwikkelen van kritisch denken over de cultuur van de ander, alsook over de eigen cultuur. De wereld is een objectief gegeven terwijl onze perceptie en cognitie daarvan subjectief zijn en beïnvloed worden door onze persoonlijke denkbeelden en door onze culturele achtergrond. De studenten zouden er dus op attent gemaakt moeten worden dat er verschillende perspectieven bestaan en dat de wereld door meerdere vensters te beschouwen is. 


\section{Literatuuropgave}

Ashmore, R.D. \& F.K. Del Boca. 1981. 'Conceptual Approaches to Stereotypes and Stereotyping'. D.L. Hamilton (Red.), Cognitive Processes in Stereotyping and Intergroup Behavior. London/New York: Psychology Press, pp. 1-35.

Allport, G. W. 1954. The nature of prejudice. Cambridge/Reading, MA: AddisonWesley.

Budimir, B. 2015. 'Nederlandse Cultuur in het Talenonderwijs in Midden-en OostEuropa'. B. Hamers (Red.), Pedagogiek van het Nederlands als vreemde taal. Centraal-Europese studenten en het Nederlands. Olomouc: Univerzita Palackého v Olomouci, pp. 3-15.

Byram, M., B. Gribkova \& H. Starkey. 2002. Developing Intercultural Dimension in Language Teaching. Strasbourg: Council of Europe.

Byram, M., C. Morgan, et. al. 1994. Teaching and Learning Language and Culture. Clevedon: Multilingual Matters.

Dlaska, A. 2000. 'Integrating culture and language learning in institution-wide language programmes'. Language, Culture and Curriculum 13, (3/2000), pp. 247263.

Ginkel, R. Van. 1996. 'Foreigners' views of the Dutch: past and present'. Dutch Crossing. A journal of Low Countries studies 20, (1/1996), pp. 117-131.

Hall, Edward T. 1990. The Silent Language. New York: Anchor Books.

Hinton, P.R. 2000. Stereotypes, Cognition and Culture. (Deel 6). London/New York: Psychology Press.

Matusitz, J. 2012. 'Relationship between Knowlegde, Stereotyping, and Prejudice in Interethnic Communication'. Pasos. Revista de Tursimo y Patrimonio Cultural 10 (1/2012), pp. 89-98.

McGarty, C., Y. Yzerbyt \& R. Spears. 2002. Social, cultural and cognitive factors in stereotype formation. C. McGarty, Y. Yzerby \& R. Spears (Red.), Stereotypes as Explanations. The formation of meaningful beliefs about social groups. Cambridge: Cambridge University Press, pp. 6-15. 